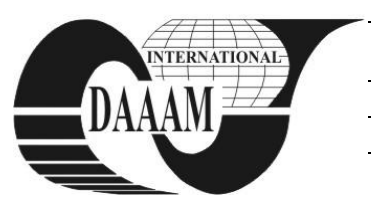

Annals of DAAAM for 2012 \& Proceedings of the 23rd International DAAAM Symposium, Volume 23, No.1, ISSN 2304-1382 ISBN 978-3-901509-91-9, CDROM version, Ed. B. Katalinic, Published by DAAAM International, Vienna, Austria, EU, 2012 Make Harmony between Technology and Nature, and Your Mind will Fly Free as a Bird

\title{
OPTIMALITY SEARCH AND ADVANCED REGULATION METHOD OF NC MILLING
}

\author{
CUS, F[ranci]; VEZA, I[vica]; PAULIC, M[atej] \& IRGOLIC, T[omaz]
}

\begin{abstract}
Owing to increasing demands and reduce of human impact on milling processes it is necessary that they are regulated and controlled by new regulation methods. In this article neural network method is described and represented on a concrete milling example. Neural network is developed and tested on measured cutting forces which occur in main coordinates. Neural network is formed to predict best cutting parameters and develop new one if necessary. With this method all logical reflection belongs to computer and trained neural network. Those methods reduce human impact and give us better results than standard optimization. During milling process neural network is trained for so long, that relative error is reduced to minimum. Relative error reduction to required values give us better final tolerance results after milling process and help us to increase milling process to higher intelligent level.
\end{abstract}

Keywords: Milling, Neural Network, Regulation, Cutting Forces, Numerical Control

\section{INTRODUCTION}

Constant desire to automate processes and replace humans at monotonous tasks led to the development of numerical controlled (NC) machines. Advantage of NC machines is that they do not require continuous intervention operator in the work process. The process runs autonomously through the control commands. Machine commands and all data needed for process (NC program) are provided in numerical form. Informations are transformed into the right format and sent to the executive element on the machine (drive or stepper electric motor).

General advantages of NC machines compared to conventional machines are:

- Productivity increase,

- Quality increase,

- More accurate scheduling,

- Flexible production planning,

- Central organization,

- Easier implementation of complex products,

- Production optimization,

- Easier control of machines,

- Able to store and reuse of NC programs,

- High repeatability and flexibility,

Simple scheme of verification of suitability of machine and cutting tools is shown in Fig. 1.

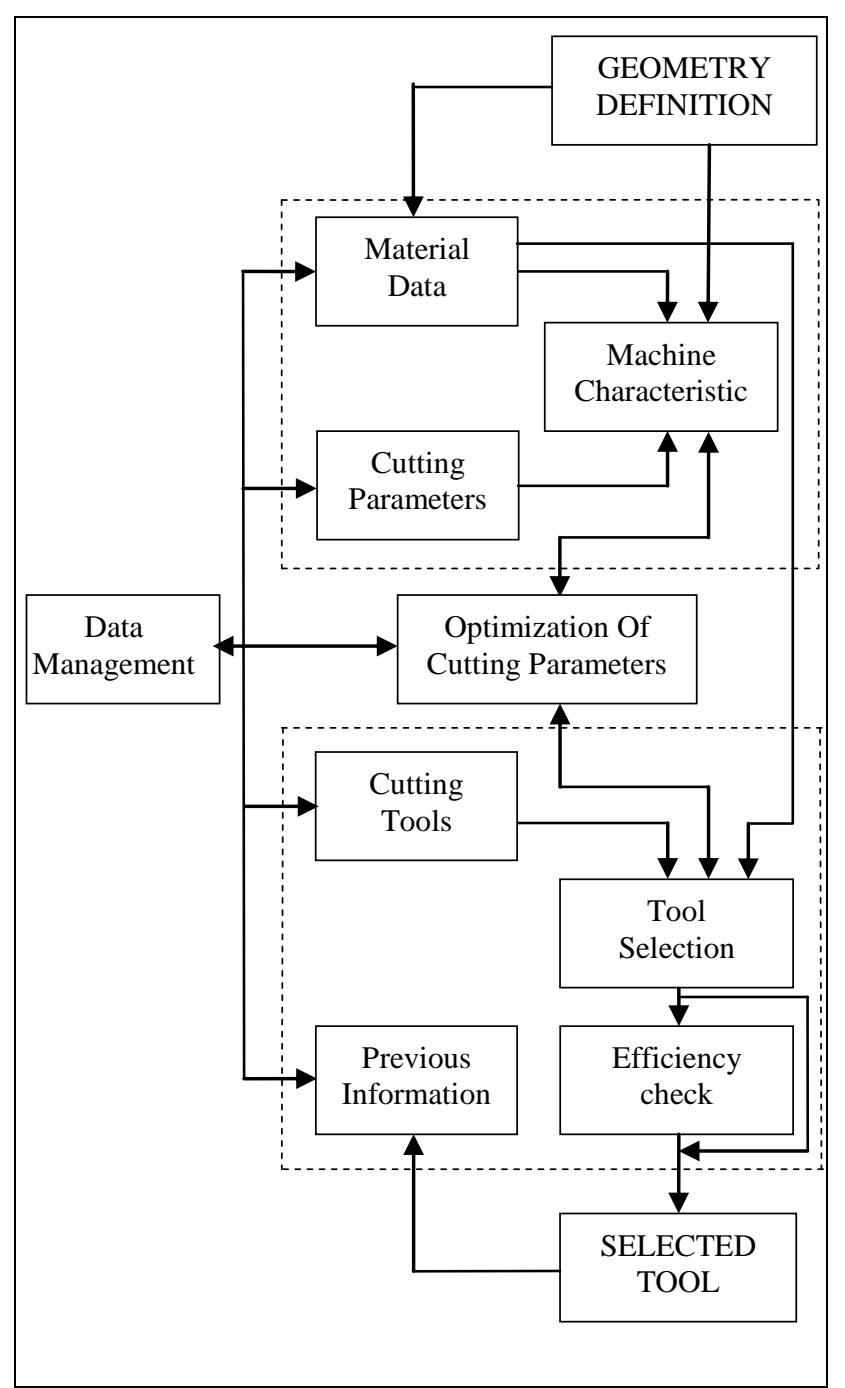

Fig. 1. Verification of suitability of machine and cutting tools

Optimization of the cutting process is a very important part of $\mathrm{NC}$ programming. In this article optimization and parameter appointment of milling processes are described $[4,11,14,17,19]$. Today is very important that parameters are well monitored $[5,12,15,16]$ and predicted.

This is difficult task for the programmer. Neural networks were developed to assist the programmer in his work. For the input into neural network, the cutting forces were chosen. On behalf of the measured forces, one can colnclude the tool load, wear and life expectancy. In this article the results of our research are presented. Measured cutting forces were processed in two different computer softwares: 
Matlab and Alyuda Neurointelligence. Our main goal was to create the neural network for milling process which can predict final cutting forces in different directions with relative error, smaller than $5 \%$.

Neural networks have the ability to distinguish and extract information from the complicated and intricated patterns. They are mainly used to search for patterns and detect trends that are too complex to be noticed by humans or other computational techniques $[1,7,8,9,13,18]$. With the help of neural networks the answer on such a question can be quickly anticipated.

The goal of our research was to use data of measured cutting forces and use them in program that could be able to predict cutting parameters in tolerance smaller than $5 \%$. It was found out that neural network is the most suitable to solve such a problem. Two different programs were used to solve our problem: Alyuda Neurointelligence and MatLab R2012a. Final results of both programs are shown in the end of paper.

\section{CHOSING PARAMETERS FOR TESTING}

Choosing an effective cutting tool plays an important role in production planning. Necessity for programs that support the selection of cutting tools is particularly acute in the usage of flexible machining cells, where a modern way of choosing the right cutting tool is required.

During our research of other papers, the decision was made to use only specific parameters. Only those parameters were chosen which can be manually changed by the operator during the machining (Tab.1). Other parameters such as work piece materials will be added in later research.

For initial testing the depth of cut and feed rate were optimized. These two parameters have the most influence on the surface roughness.

For our research 36 measured results were used. Cutting forces were measured with dynamometer Kistler 9257A shown in Fig. 2.Spindle speed was 2000 rpm. All measured cutting forces at different depth of cut and feed rate are shown in Tab 1.

Automatic selection of tools for each operation can be done in several ways. The simplest way is to select the first tool that corresponds to the required product geometry. In recent times more additional conditions for the selection were considered. Additional conditions for selection of the proper cutting tools are:

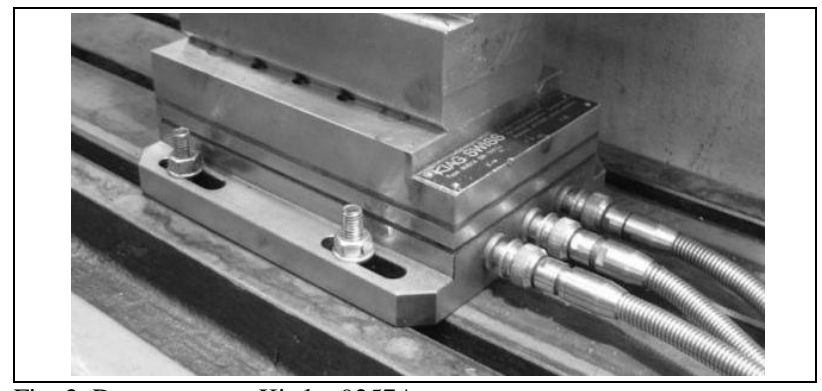

Fig. 2. Dynamometer Kistler 9257A

- The maximum amount of material removal,

- Maximum tool life.
For work piece material a steel alloy with hardness ranged from 40 to $42 \mathrm{HRC}$ was chosen. Wet cutting conditions were chosen.

\begin{tabular}{|c|c|c|c|c|c|}
\hline \multicolumn{3}{|c|}{ Cutting parameters } & \multicolumn{3}{|c|}{$\begin{array}{c}\text { Cutting forces in } \mathrm{X}, \mathrm{Y}, \mathrm{Z} \\
\text { directions }\end{array}$} \\
\hline num. & $\mathrm{a}_{\mathrm{p}}(\mathrm{mm})$ & $\begin{array}{c}\mathrm{f} \\
(\mathrm{mm} / \mathrm{min})\end{array}$ & $\mathrm{X}[\mathrm{N}]$ & $\mathrm{Y}[\mathrm{N}]$ & $\mathrm{Z}[\mathrm{N}]$ \\
\hline 1 & 0,25 & 100 & 545,3 & 148,6 & 51,3 \\
\hline 2 & 0,25 & 150 & 561,7 & 173,1 & 62,5 \\
\hline 3 & 0,25 & 250 & 583,9 & 196,7 & 69,7 \\
\hline 4 & 0,25 & 500 & 628,8 & 211,4 & 77,9 \\
\hline 5 & 0,25 & 750 & 694,5 & 255,7 & 87,7 \\
\hline 6 & 0,25 & 1000 & 765,1 & 302,2 & 98,6 \\
\hline 7 & 0,5 & 100 & 841,6 & 305,9 & 117,5 \\
\hline 8 & 0,5 & 150 & 893,6 & 308,6 & 134,9 \\
\hline 9 & 0,5 & 250 & 962,0 & 315,1 & 156,4 \\
\hline 10 & 0,5 & 500 & 1081 & 323,3 & 180,8 \\
\hline 11 & 0,5 & 750 & 1187,4 & 352,1 & 207,5 \\
\hline 12 & 0,5 & 1000 & 1243,6 & 398,4 & 267,8 \\
\hline 13 & 0,75 & 100 & 1303,7 & 428,6 & 302,7 \\
\hline 14 & 0,75 & 150 & 1394,7 & 489,3 & 365,7 \\
\hline 15 & 0,75 & 250 & 1472,2 & 536,7 & 403,4 \\
\hline 16 & 0,75 & 500 & 1568,8 & 595,5 & 443,3 \\
\hline 17 & 0,75 & 750 & 1652,9 & 653,4 & 521,6 \\
\hline 18 & 0,75 & 1000 & 1742,8 & $\begin{array}{l}774,3 \\
\end{array}$ & 615,2 \\
\hline 19 & 1 & 100 & 1814,2 & 832,4 & 705,8 \\
\hline 20 & 1 & 150 & 1879,3 & 889,1 & 794,6 \\
\hline 21 & 1 & 250 & 1987,2 & 952,3 & 856,4 \\
\hline 22 & 1 & 500 & 1973,8 & 1023,6 & 901,3 \\
\hline 23 & 1 & 750 & 2087,6 & 1068,7 & 968,7 \\
\hline 24 & 1 & 1000 & 2165,1 & 1102,7 & 1009,1 \\
\hline 25 & 1,5 & 100 & 2224,0 & 1153,6 & 1085,3 \\
\hline 26 & 1,5 & 150 & 2301,8 & 1204,5 & 1145,7 \\
\hline 27 & 1,5 & 250 & 2397,3 & 1247,3 & 1214,3 \\
\hline 28 & 1,5 & 500 & 2461,1 & 1284,3 & 1287,6 \\
\hline 29 & 1,5 & 750 & 2533,9 & 1311,3 & 1352,0 \\
\hline 30 & 1,5 & 1000 & 2642,6 & 1374,6 & 1448,4 \\
\hline 31 & 2 & 100 & 2812,5 & 1437,2 & 1584,9 \\
\hline 32 & 2 & 150 & 3001,8 & 1489,7 & 1712,3 \\
\hline 33 & 2 & 250 & 3138,6 & 1533,4 & 1842,7 \\
\hline 34 & 2 & 500 & 3314,3 & 1573,6 & 1958,6 \\
\hline 35 & 2 & 750 & 3522,4 & 1638,4 & 2040 \\
\hline 36 & 2 & 1000 & 3785,2 & 1745,8 & 2115,6 \\
\hline
\end{tabular}

Tab. 1. Cutting parameters and cutting forces in $\mathrm{X}, \mathrm{Y}, \mathrm{Z}$ directions

\section{SOFTWARE TESTING}

For testing in Alyuda Neurointelligence scheme of neurons arrangement is shown in Fig. 3. There were two entrances and one exit. At one entrance was depth of cut $\left(a_{p}\right)$ and at the other was feed rate (f).

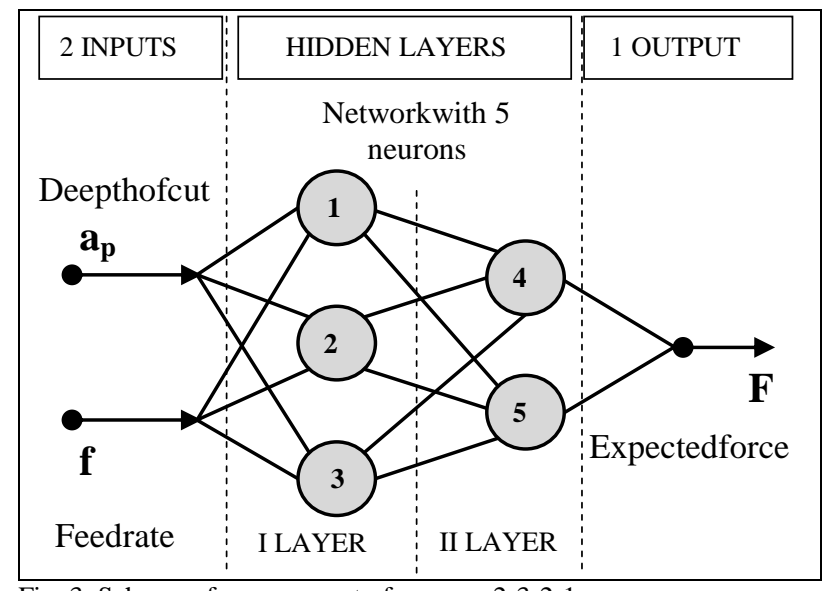

Fig. 3. Scheme of arrangement of neurons 2-3-2-1 
With neural network shown in Fig. 3 several different methods were used: Quasi Newton, Levensberg Propagation, Conjugate Gradient Descent, et. al. Final results of actual error of all methods are shown in Tab. 2. This neural network has two hidden layers between entrance and exit.

Second part of research was made in Matlab R2012a. Neural network with 38 layers give us the best results, where the relative error was less than $5 \%$. Scheme of this neural network is shown in Fig. 4. There were two entrances and one exit. The processed parameters were the same like in research with Alyuda Neurointelligence and are shown in Tab. 1.

Part of the program written in Matlab is shown in Fig. 5. In comparison with neural networks made with Alyuda Neurointelligencethis neural network is more complex and it has more layers.

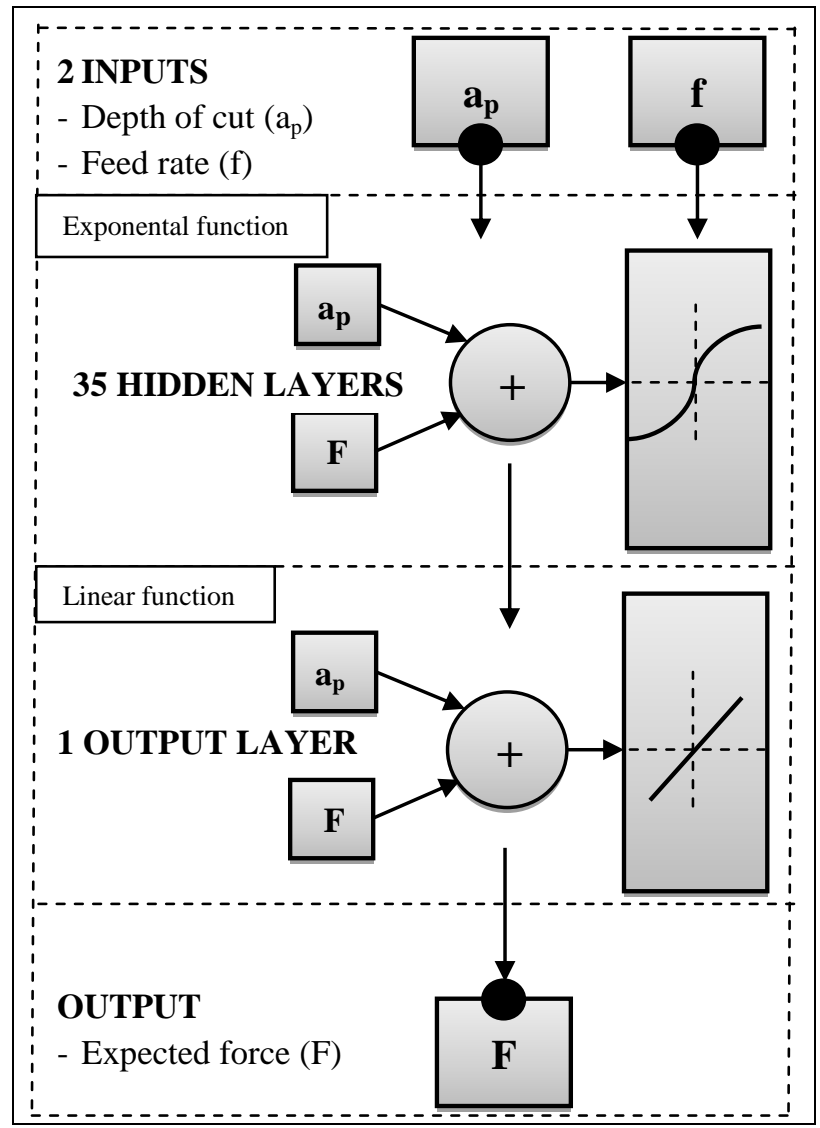

Fig.4. Scheme of neural network with 38 layers tested in Matlab

Negative site of such a complex neural network is the data treatment which is too complicated for normal personal computer and NC machine controller.

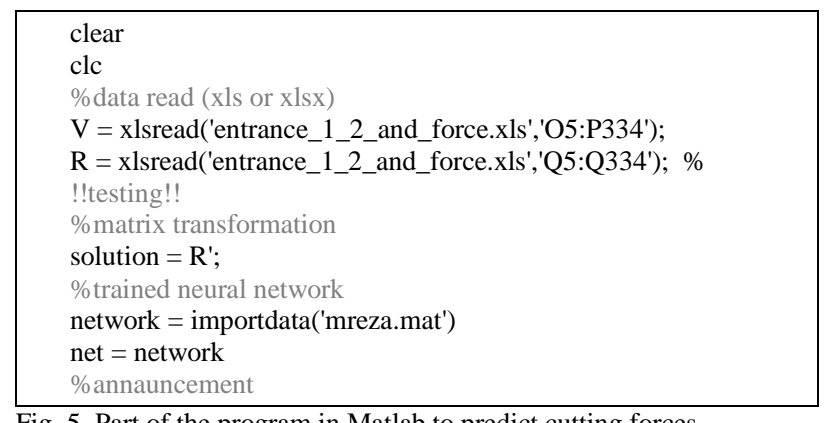

Fig. 5. Part of the program in Matlab to predict cutting forces

\section{RESULTS}

The most important results of our research are graphically treated and shown in diagrams. Validation performance for Quasi Newton method during learning is shown in Fig. 6.

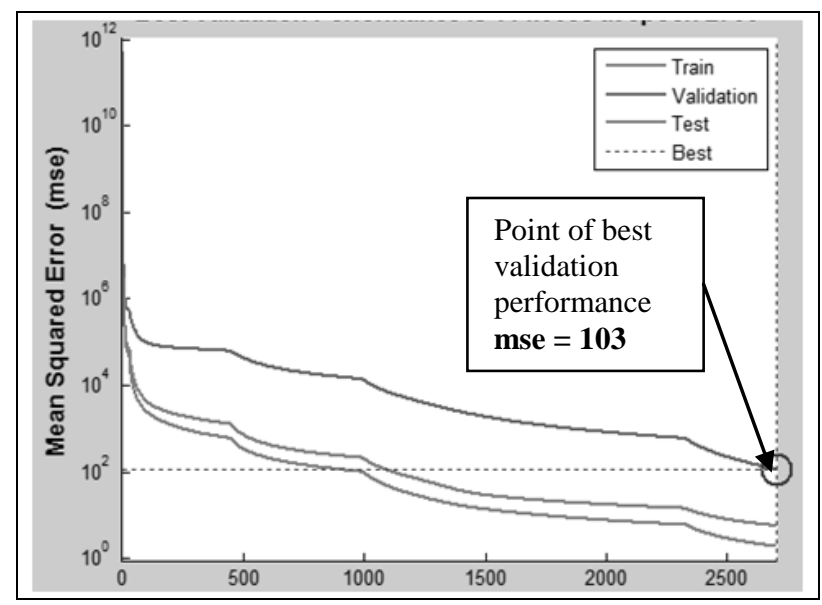

Fig. 6. Best validation performance

Using the software package Alyuda Neurointelligence has made a number of useful results. Four methods give us great results with relative error less than $5 \%$.Resaults of our research are shown in Tab. 2 .

\begin{tabular}{|c|c|}
\hline Method & Actual error in \% \\
\hline Quasi Newton & 3,44 \\
\hline Levenberg Propagation & 3,92 \\
\hline Conjugate Gradient Descent & 4,09 \\
\hline Online Back Propagation & 4,72 \\
\hline Quick Propagation & 18,56 \\
\hline Batch Back Propagation & 20,36 \\
\hline
\end{tabular}

Tab.2. Actual error in \% for individual method

During the research it was found out that system for optimization the machining parameters must consider a variety of restrictions, such as:

- Standard which is set by the user,

- The variation in the use of new tools,

- Special database,

- Processing parameters,

- Work piece geometry.

Histogram in Fig. 7 show us numbers of errors during

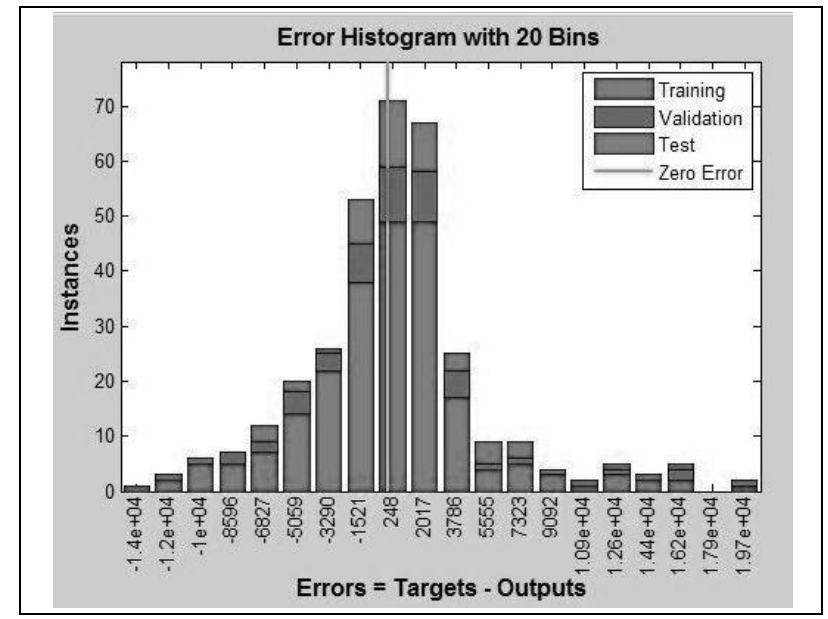

Fig. 7. Histogram of errors during learning process 
neural network learning, validation and testing. As it can be seen on the histogram, maximum error occurs during learning process.

Neural network made with Matlab give us better results than neural network made with Alyuda Neurointelligence. Relative error at the best neural network in Matlab was 2,15\%. However neural network in Matlab is more complex in it takes more time to solve it.

Best validation performance reached in Matlab is at epoch 127 and it is shown in Fig. 8. At this point is the smallest difference between validation squared errors and trained squared errors.

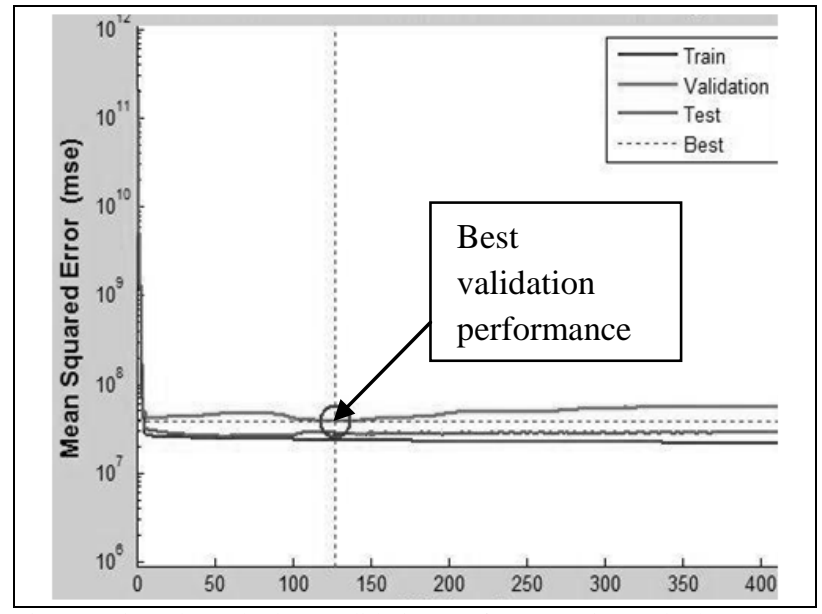

Fig. 8. Point where the best validation performance is reached

\section{CONCLUSION}

By using the combination of different neural network methods and two different software, a reliable system for prediction cutting forces was established.

Final results of actual errors shown in Tab. 2 tell us, that there is a lot of free space to reduce actual errors. Our next step is to build neural network which will contain additional cutting parameters, what will actually give us better results. But on the other side this mean that neural network will became more complex and the calculating time will extend. So the suitable compromise between selected cutting parameters and tolerance of results will have to be made.

For further work additional programs (new neural networks, genetic algorithms, new methods) and tests will be realized to reduce errors of expected cutting forces to minimum and to achieve greater stability of the whole process. Our goal is to apply developed neural networks in other cutting processes (drilling, turning and grinding) to evaluate the option of developing a single program for different machine operations.

\section{REFERENCES}

[1] Mukherjee, I.;Ray, P. K. (2006)A review of optimization techniques in metal cutting processes, Computers \& Industrial Engineering 50, 2006, pp. 15-34

[2] Cus, F.; Zuperl, U. \& Gecevska, V. (2009). Self-Learning Control Strategy with Application to Milling System, Annals of DAAAM for 2009 \& Proceedings of the 20th International DAAAM Symposium, 25-28th November 2009, Vienna, Austria, ISSN 1726-9679, ISBN 978-3-901509-70-4, Katalinic, B. (Ed.), pp. 0451-0452, Published by DAAAM International Vienna, Vienna
[3] Kromanis, A.; Krizbergs, J. (2009). Prediction of Surface Roughness in End-Milling using Fuzzy Logic and its Comparison to Regression Analysis, Annals of DAAAM for 2009 \& Proceedings of the 20th International DAAAM Symposium, 2528th November 2009, Vienna, Austria, ISSN 1726-9679, ISBN 978-3-901509-70-4, Katalinic, B. (Ed.), pp. 0803-0804, Published by DAAAM International Vienna, Vienna

[4] Fabian, M.; Spisak, E.; Seminsky, J.; Senderska, K.; Mares, A. \& Izol, P. (2010). CAM Parameters Settings and NC Milled Surface Quality, Annals of DAAAM for 2010 \& Proceedings of the 21st International DAAAM Symposium, 20-23rd October 2010, Zadar, Croatia, ISSN 1726-9679, ISBN 978-3-901509-73-5, Katalinic, B. (Ed.), pp. 0391-0392, Published by DAAAM International Vienna, Vienna

[5] Xu C., Chen H., Liu Z., Cheng Z. (2009). Condition monitoring of milling tool wear based on fractal dimension of vibration signals, Strojniški vestnik - Journal of Mechanical Engineering 55 (2009), Vol. 1, pp. 15-25

[6] Daraba, D. \& Boca, G. D. (2010). Experimental Assessment of the Milling Machine Column Before Remanufacturing, Annals of DAAAM for 2010 \& Proceedings of the 21st International DAAAM Symposium, 20-23rd October 2010, Zadar, Croatia, ISSN 1726-9679, ISBN 978-3-901509-73-5, Katalinic, B. (Ed.), pp. 0733-0734, Published by DAAAM International Vienna, Vienna

[7] Zuperl, U.; Cus, F. \& Balic, J. (2010). Neural Network Based Control Algorithm in Robotised Unmanned Flexible Manufacturing System, Annals of DAAAM for 2010 \& Proceedings of the 21st International DAAAM Symposium, 2023rd October 2010, Zadar, Croatia, ISSN 1726-9679, ISBN 9783-901509-73-5, Katalinic, B. (Ed.), pp. 0305-0306, Published by DAAAM International Vienna, Vienna

[8] Zuperl, U.; Cus, F.; Kiker, E. (2009) Adaptive network based inference system for estimation of flank wear in end-milling, 2009, Journal of Materials Processing Technology, Vol. 1, Issue 3, pp.1504-1511

[9] Zuperl, U.; Cus, F.; Reibenschuh, M.(2011). Neural control strategy of constant cutting force system in end milling, 2011, Robotics and Computer-Integrated Manufacturing, Vol. 27, Issue 3, pp. 485-493

[10] Zuperl, U.; Cus, F.; Mursec, B.; Ploj, T. (2006) A generalized neural network model of ball-end milling force system, 2006, Journal of Materials Processing Technology 2006, Vol. 175, Issues 1-3, pp. 98-108

[11] Zuperl, U.; Cus, F. (2012). System for off-line feedrate optimization and neural force control in end milling, International Journal of Adaptive Control and Signal Processing (2012), Vol. 26 Issue 2, pp. 105-123

[12] Chuangwen, X.; Wu, X.; Lou, W. (2008) Milling wear monitoring study based on artificial neural network,Fourth International Conference on Natural Computation 2008

[13] Balic, J. (2004) Neural-network-based numerical control for milling machine, Journal of Intelligent \& Robotic Systems (2004), Vol. 40, No. 4, pp. 343-358

[14] Cus, F.;Zuperl, U.Approach to optimization of cutting conditions by using artificial neural networks 2006, J Mater Process Technol (2006), Vol. 173, Issue 3, pp. 281-290

[15] Guofeng, W. (2012). On line tool wear monitoring based on auto associative neural network, Journal of Intelligent Manufacturing 2012

[16] Brezak, D., Udiljak, T., Majetic, D., Novakovic, B., \& Kasac, J. (2004). Tool wear monitoring using radial basis function neuralnetwork, Neural Networks2004, Vol. 3, pp. 1859-1862

[17] Cios, K.J., Liu, N. A (1992). Machine Learning Method for Generation of a Neural Network Architecture: A Continuos ID3 Algorithm,IEEE Transactions on Neural Networks, 1992, Vol. 3, No. 2, pp. 280-291

[18] Balazinski, M., Czogala, E., Jemielniak, K., Leski, J. (2005).Toolcondition monitoring using artificial intelligence methods

Engineering Applications of Artificial Intelligence (2005), Vol. 15 , pp. $73-80$

[19] Cus, F., Balic, J. (2000). Selection of cutting conditions and tool flowin flexible manufacturing system. International Journal for Manufacturing Science and Technology 2000, Vol. 2,pp. 101-106 